\title{
$\mathfrak{I} \mathfrak{n} \mathfrak{b} \mathfrak{a} \mathfrak{l} \mathfrak{t}$
}

\section{Crifteb 5eft.}

Die Seidsarmee im flebenjäbrigent \$rieg. (Deinrid boul Eiđent.) . . . . Seite 1

Die Sdulbebatte im Ibgeorbnetenbaufe. (Dr. Ronrab Riemeber.) . . . . - 15

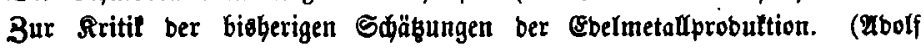

Goetbeer.) . . . . . . . . . . . . . . . . . . - 26

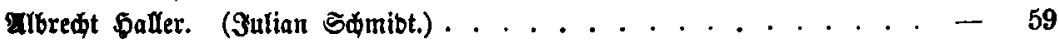

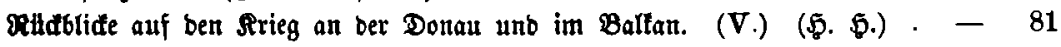

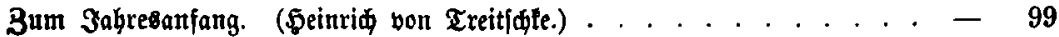

3u ben \$eptaben. (Fr. Barnde.) . . . . . . . . . . . . 108

Entgegnung. (Nub. פenting.) . . . . . . . . . . . . . -109

Rotizerl. . . . . . . . . . . . . . . . . -111

3 wette 5 eft.

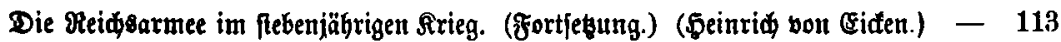
Friebriф $\mathfrak{B i l g e l m}$ III. im Sahre 1809. (MRax Dunder.) . . . . . . . . - 136

Ehateaubrianb. (F̧ortiekung.) (Theobor v. Bernbarbi.) . . . . . . . -160 Rllablicte auf Sen Sirieg an ber Doutau unb im Baftan. (VI.) (\$. Đinze.) - 187 Pio Nono. (Sutian Sđmibt.) . . . . . . . . . . . . . -211 Cinige Bemertungen über Reidfftempelfteutrn. . . . . . . . . . . -216 Notigen. (๔.) . . . . . . . . . . . . . . . . . -222

\section{Drittes seft.}

Birtungen bes allgemeinen Stimmredits auf bie Berwaltuntg amerilanifder

Stäbte. (Friebrid ßapp.) . . . . . . . . . . . . . - 225

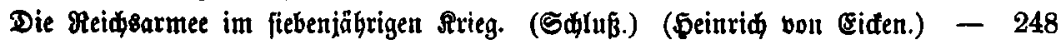

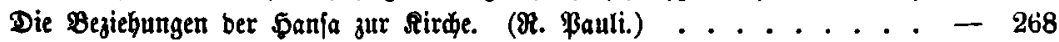

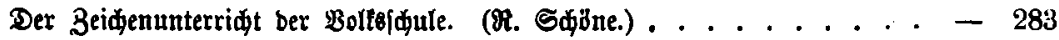

Riltäbliđe auf ben Sirieg an ber Donau unb im Baltan. (VII.) (פ. Ginge.) - 298

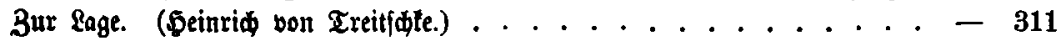
Notizen. . . . . . . . . . . . . . . . . . -324 


\section{Biertes \$eft.}

Daß Drbenslanb ßreußen unb bie \$anje bis zum 3abre 1370. (Dr. (E. Sattler.) 'Seite 327 \$oln Bromn. (\$. v. \$olft.) . . . . . . . . . . . . . . . -350

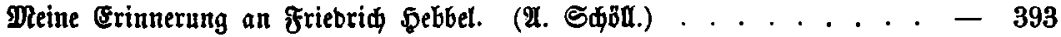
Die neuefte Epradpbilojopbie. (§. Brudmann.) . . . . . . . . . 409 Manin und Pallabicino. (ær. Lang.) . . . . . . . . . . . . - 421 Die finftige Drganifation ber Breufifdent Staat\&=(Eifenbabn-Berwaltung.

(b. $\mathfrak{M}$.)

Filnftę \$eft.

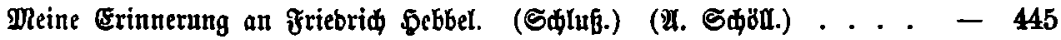
Die moberne Rehre bom Stoff. (\$. \$artung.) . . . . . . . . . . . 462 Repnin unb bie (5zartorb8ti, 1794-1797. (Dr. Ridarb Roepell.) . . . - 485

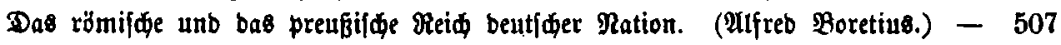
Der Brälimiutarbertag bon San Stefano. (5. \$inze.) . . . . . . . . - 529 Politifde Correfponbent. (Der Drient uno bie europäifde \&age feit bent Frieben bon San Stefano.) (F. -r.) . . . . . . . . . . - 542

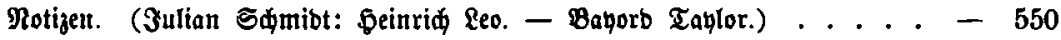

Sediftez Soeft.

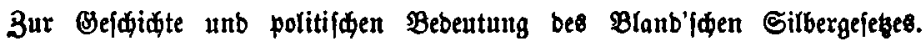

(5. v. Eolf.) . . . . . . . . . . . . . . . . . . 553 Siebenbitrgen unb ber Dualismus in Deferreid. . . . . . . . . . . -591

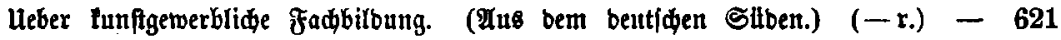
Der Socialismus unb ber Meudelmorb. (\$einrid bon Treit|dle.) . . . - 637 Rotizen. (Die Meiniuger - (Soethe-Sqolien.) (Sutian Sфmibt.) . . . 648 